\title{
TISSUE PRESSURE (INTRACUTANEOUS, SUBCUTANEOUS, AND INTRAMUSCULAR) AS RELATED TO VENOUS PRESSURE, CAPILLARY FILTRATION, AND OTHER FACTORS ${ }^{1,2}$
}

\author{
By HERBERT S. WELLS, JOHN B. YOUMANS, AND DAVID G. MILLER, JR. \\ (From the Departments of Physiology and Medicine, Vanderbilt University School of Medicine, \\ Nashville)
}

(Received for publication March 11, 1938)

Tissue pressure has often been discussed as a factor of importance for limiting the filtration of fluid from the capillaries. Calculations $(1,2)$ have indicated that the tension in the tissues resulting from accumulation of fluid may attain high values, but available data from direct measurements seem to show that tissue pressure is not always significantly elevated by prolonged venous congestion and that even in edema the values are not nearly as high as would be expected $(3,4,5)$. The striking discrepancy between theory and experiment has led some authors to discount the importance of tissue pressure; but it should be borne in mind that the published experimental data refer only to subcutaneous and intracutaneous pressures, and that intramuscular pressure has not previously been measured in relation to problems of capillary filtration.

1 This work has been aided by a Fluid Research Fund of the Rockefeller Foundation.

2 A preliminary report was presented before the American Physiological Society at Memphis in April, 1937.
The present paper deals with measurements of the pressure in muscle as well as in the superficial tissues. The studies have been confined chiefly to observations on normal human subjects; and our interest has centered mainly on tissues of the leg, because of the well known paradox of the failure of edema to develop in legs of normal individuals on prolonged quiet standing. This problem has been the subject of previous communications in which we have invoked tissue pressure as one of the factors limiting filtration in the leg $(2,6)$.

\section{METHODS}

Two methods were employed for measuring tissue pressure. In the standard method a fine needle, connected to a capillary glass tube, is introduced into the tissue in a horizontal position as indicated in Figure 1. Movements of minute amounts of saline into and out of the tissue are controlled by varying the pressure applied from a water manometer. Since a change of 2 or $3 \mathrm{~mm}$. $\mathrm{H}_{2} \mathrm{O}$ suffices to reverse the flow, at the point of balance, an accurate estimate of tissue pressure is readily obtained. Changes of direction of movement of the meniscus, as observed with a cathetometer, occur within a few seconds

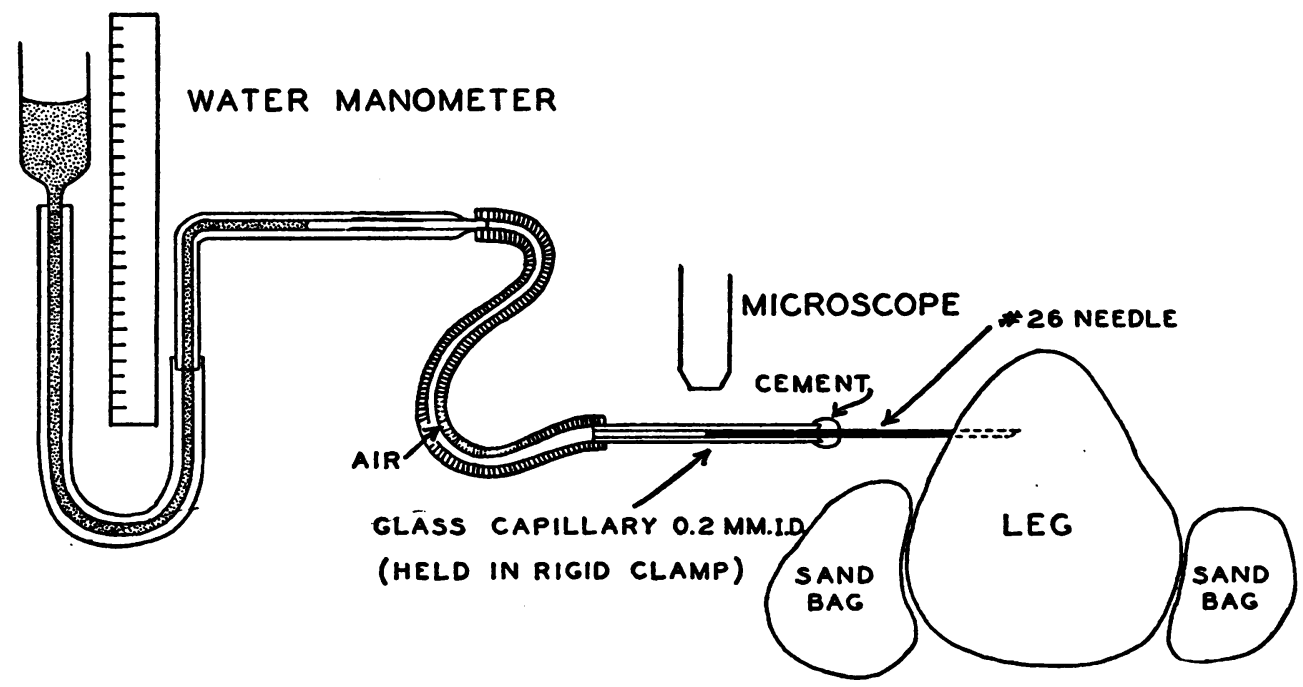

Fig. 1. Diagram Showing Method of Determining Tissue Pressure 
after the manometer pressure is altered. A correction is applied to the manometer reading to allow for the capillarity of the glass tube. Hundreds of measurements have been made with this device since 1932, and we feel confident from this experience that the method measures true tissue pressure, provided several obvious sources of error are eliminated. For example, if gross bleeding is induced the measured pressure will be abnormally high and variable and the bore of the needle is apt to become plugged. However, local hemorrhage is usually minimal and its results temporary. It is our practice to pull all available fluid into the system before withdrawing the needle, and in successful experiments this fluid is very slightly colored and contains only a few red cells. In earlier experiments the precaution was taken of rendering the limb bloodless by wrapping with a rubber bandage and removing part of the bandage from below to expose an area for measurement of the tissue pressure. Pressure values obtained from all tissues of the bloodless limb are the same as, or but slightly lower than, values obtained after the circulation has been restored. In later experiments we have rarely employed the rubber bandage: the needle has been inserted with the circulation intact. Bleeding occurs quite frequently but its signs are easily detected so that errors are avoided simply by reinserting the needle until a "bloodless" area is located. In the case of muscles of the forearm, however, which seem to bleed very readily, we have attempted to measure only the pressure developed during maximal voluntary contraction of these muscles, when bleeding can interfere but slightly with the accuracy of the measurement.

For the standard method, the limb must be firmly fixed so that observed movements of the meniscus in the capillary tube can be safely attributed only to true movements of the fluid column. The subject lies on a rigid table, padded but without springs, and the limb to be studied is held immobile by supporting cushions and sandbags. The needle assembly, which includes a reference scale not shown in the diagram, is clamped rigidly in a horizontal position. The limb must not rest upon the table near the point of the measurement, for deformation of the tissues by the weight of the limb may transmit abnormally high pressures to the region under study. Local pressure may be changed by the needle itself, but such errors may be avoided by observation of the skin surface at the point of insertion. If the skin is puckered inward the local pressure will be elevated, and conversely if the skin is raised by partial withdrawal of the needle the pressure will be lowered even to subatmospheric levels. Lateral pressure of the needle must also be avoided. In all cases the local pressure will adjust itself to the equilibrium value if sufficient time (an hour or so) is allowed-presumably through movements of tissue fluid.

Local anesthesia is rarely necessary if care is taken to seek out areas of skin and fascia which are free from pain endings. These tissues are much less sensitive in the leg than in the arm. Sharp pain which persists and often increases after insertion of the needle is usually indicative of gross hemorrhage. In a successful experi- ment the subject may feel no pain whatever-the needle may sometimes be inserted deep into a muscle while the subject sleeps.

The second method allows experiments to be carried out on the standing or moving subject, since the observations do not require fixation of the limb. Several cubic millimeters of fluid may be injected into subcutaneous tissue or muscle during the course of the experiment. The fluid flows in from the vertical manometer tube depicted in Figure 2. It is obvious that great care must be

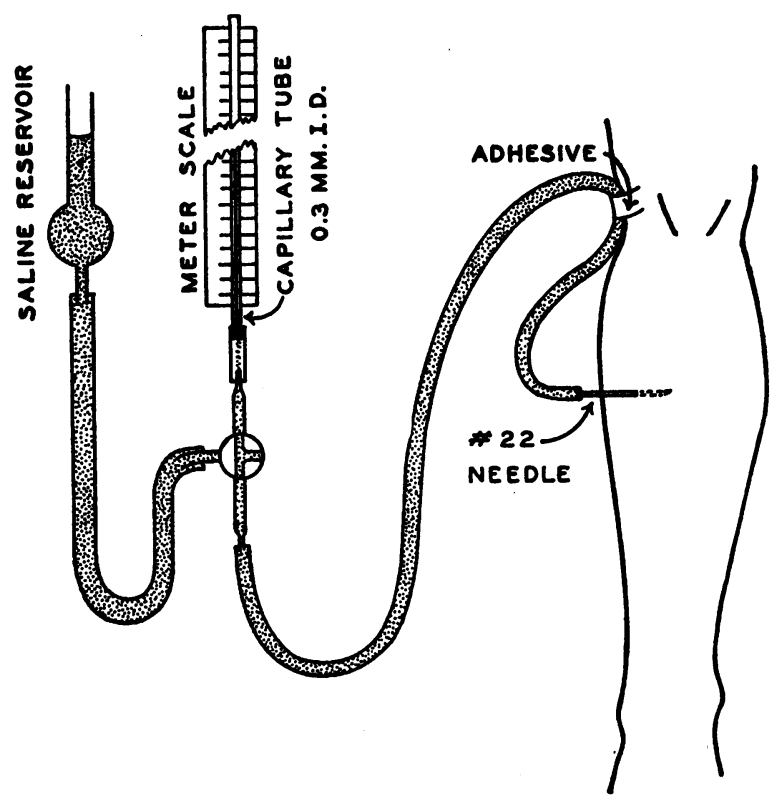

Fig. 2. Diagram of Alternative Method for Use on Standing or Moving Subjects

employed lest the injected fluid raise the local pressure permanently above its original level. The fluid must be able to flow freely into surrounding tissues and to return freely into the system, so that the equilibrium pressure may be approached from pressures below, as well as from pressures above, the point of balance. Larger needles are used than in the first method, and 2 or 3 small holes are bored in each, laterally near the tip (using a pointed sewing needle as drill), to facilitate the passage of fluid into and out of the tissues. The higher the tissue pressure the greater the possibility of error through injection of an excessive amount of fluid. Fortunately the tissue fluid itself, or fluid previously injected, will flow into the system with sufficient ease to allow the marked rise of intramuscular pressure occurring during standing to be recorded without the necessity for repeating the injections. The accuracy of the second method has been checked repeatedly against the standard method in recumbent subjects. The checks have been satisfactory over the whole range of values of tissue pressure which we have encountered.

The best test of the validity of the methods is perhaps that of recording intramuscular pressure at various levels 
of venous pressure. The fact that tissue pressure rises to the same levels with repeated elevations to the same levels of venous pressure, and that these values are always lower than venous pressure, convince us that extraneous, uncontrolled factors can play but a small part in determining the measured pressures. It might be argued that the pressure values obtained by our methods provide an erroneous measure of true tissue tension because of the tearing apart of the tissue elements by the needle or the injected fluid; but actually the results, in any experiment, are discarded unless it can be demonstrated that the fluid injected locally has free access to surrounding, uninjured tissue.

With the exception of three edematous patients on whom measurements of subcutaneous pressure were made, our subjects were all normal males, ranging in age from 20 to $\mathbf{4 5}$ years. Sedentary individuals and persons of good muscular development were included. The experiments were conducted, in most instances, at room temperatures ranging from $25^{\circ}$ to $30^{\circ} \mathrm{C}$.

\section{RESULTS}

Subcutaneous pressure. Figure 3 shows the distribution of values of subcutaneous pressure as measured in the forearm and leg of normal subjects; in the most edematous regions of two

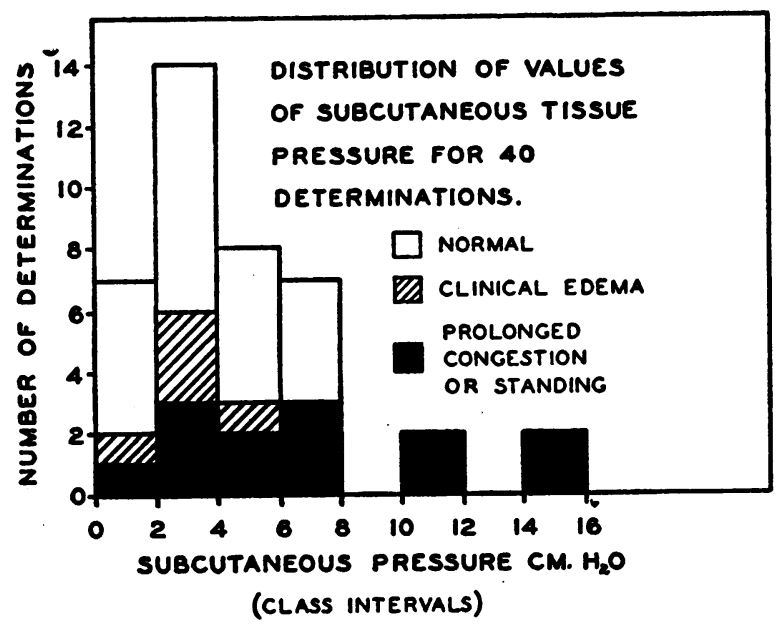

Fig. 3. Histogram Showing Distribution of Values of Subcutaneous Pressure

ambulatory patients showing slight clinical edema of the extremities; and in the arms and legs of normal subjects following prolonged venous congestion produced by inflation of a blood pressure cuff to pressures from 50 to $100 \mathrm{~cm} . \mathrm{H}_{2} \mathrm{O}$, or by quiet standing, for periods from one to three hours in duration. Nearly half the values range from 2 to $6 \mathrm{~cm} . \mathrm{H}_{2} \mathrm{O}$. In general, our findings are similar to those of Meyer and Holland $(3,4)$ who report values for normal and edematous subjects which average $3 \mathrm{~cm} . \mathrm{H}_{2} \mathrm{O}$, and to those of Burch and Sodeman (5) which range from 1 to $7 \mathrm{~cm} . \mathrm{H}_{2} \mathrm{O}$ in normal subjects. The findings of Smirk (7) and of Burch and Sodeman indicate clearly that in developing edema the subcutaneous pressure may rise to higher levels, especially when the measurement is made with the limb in a dependent position. They found maximum values of $18 \mathrm{~cm}$. and $26 \mathrm{~cm} . \mathrm{H}_{2} \mathrm{O}$ respectively. Holland and Meyer (4) report a case of massive edema in which subcutaneous pressure rose to $20 \mathrm{~cm} . \mathrm{H}_{2} \mathrm{O}$.

We find, in accord with Burch and Sodeman but contrary to Meyer and Holland, that subcutaneous pressure rises somewhat with venous congestion. The rise is not great-usually not more than 1 to $3 \mathrm{~cm} . \mathrm{H}_{2} \mathrm{O}$-but values of $11 \mathrm{~cm}$. and $15 \mathrm{~cm} . \mathrm{H}_{2} \mathrm{O}$ were found in the tissues overlying the gastrocnemius and anterior tibial muscles respectively in one subject after nearly three hours of quiet standing. Figure 4 shows that in the arm subcutaneous pressure may rise as soon as venous congestion is initiated, and will fall at once on release of the congesting cuff pressure, although the plethysmograph shows that the arm volume has progressively increased nearly $100 \mathrm{cc}$. It is concluded that a rise in venous pressure, through its direct effect to swell the limb, may raise subcutaneous pressure slightly, but that the fluid filtered into the limb during congestion may, up to certain limits, have little or no effect to raise this pressure further. It is probable that subcutaneous pressure can offer no effective resistance to filtration until edema fluid stretches the overlying skin to near the limit of its normal elasticity.

Intracutaneous pressure. We have made few measurements of normal intracutaneous pressure. The values observed lie in the range reported by Meyer and Holland (3) for normal subjects, viz., 5 to $9 \mathrm{~cm} . \mathrm{H}_{2} \mathrm{O}$. Following prolonged congestion of the leg, in six experiments, values from 7 to $12.5 \mathrm{~cm} . \mathrm{H}_{2} \mathrm{O}$ were obtained, the highest figure referring to pressure in the skin over the gastrocnemius after standing 100 minutes. As in the case of subcutaneous pressure venous congestion produces an immediate rise in intracutaneous tension, rises of 2 to $3 \mathrm{~cm}$. respectively having been recorded on application to the thigh of a congesting pressure of $100 \mathrm{~cm} . \mathrm{H}_{2} \mathrm{O}$ in experiments on two individuals. We have not measured intracutane- 


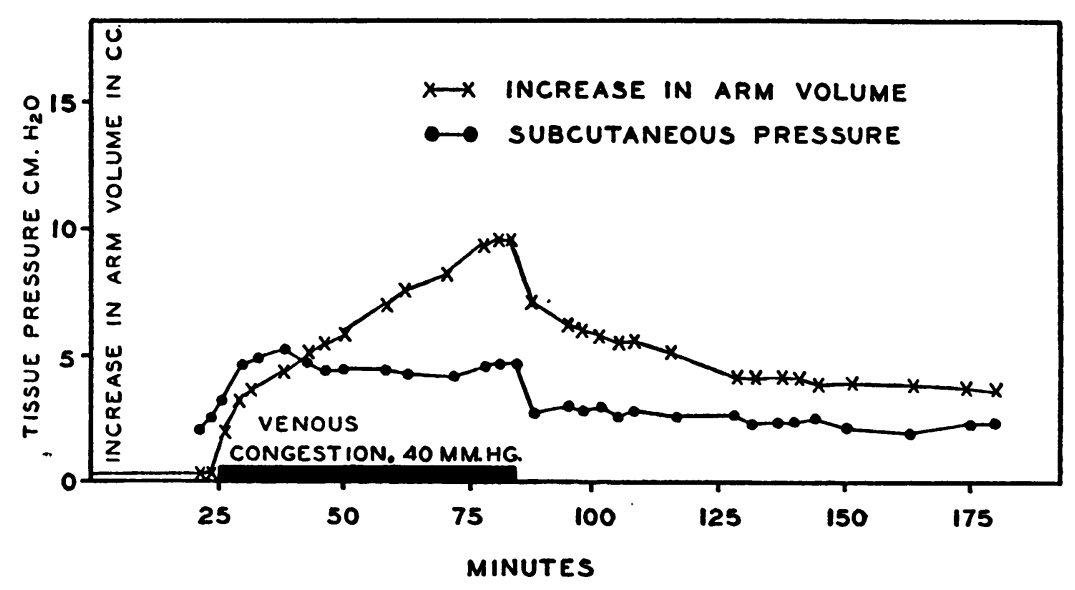

Fig. 4. Increase of Arm Volume (cc. $\times 10$ ) and Subcutaneous Pressure DURing Venous Congestion

ous pressure in edematous subjects, but Holland and Meyer (4) report that pressures in edematous skin are below normal levels, presumably as the result of the breaking apart of elastic elements by the accumulating fluid.

It seems evident that intracutaneous pressure is a factor of minor importance for retarding the development of edema.

Intramuscular pressure. (a) In the normal, relaxed subject in the recumbent posture. Under these conditions intramuscular pressure values have been found to vary, in different individuals and in the same person on different days, from 2 to $11 \mathrm{~cm} . \mathrm{H}_{2} \mathrm{O}$. Values below $5 \mathrm{~cm} . \mathrm{H}_{2} \mathrm{O}$ were found in most studies on muscles, such as the biceps brachii, and the gastrocnemius, which have a thin or loose fascial covering. The higher values, usually from 5 to $10 \mathrm{~cm}$. $\mathrm{H}_{2} \mathrm{O}$, refer to measurements on the anterior tibial and soleus, which are invested with a tight fascial sheath.

It is probable that, as Henderson, et al. (8) suggest, variations in muscle tonus may affect intramuscular pressure of the recumbent, relaxed subject; but our experience leads us to believe that tonus is often absent in limb muscles of normal individuals under these conditions, and that even under conditions leading to postural contraction of the muscles the level of intramuscular pressure serves as a very unreliable measure of the tonus. Intramuscular pressure in the relaxed subject appears to be determined by a variety of factors of which the most important are the tightness of the overlying fascia, the amount of extravascular fluid present in the muscle, and the degree of filling of its blood vessels.

(b) Effect of venous pressure on intramuscular pressure. Intramuscular pressure responds immediately to changes in venous pressure, even to those relatively slight fluctuations due to respiration. The response is much greater than that of subcutaneous or intracutaneous pressure in muscles like the soleus and the anterior tibial which possess tight fascial sheaths, but in the gastrocnemius the changes are minimal. The immediate effects of raising venous pressure by applying successive increments of pressure to a congestion cuff, with the subject in the recumbent position, or by allowing the subject to assume the erect posture, are shown in Figure 5, which presents data from a typical experiment. In this instance venous pressure was recorded directly from a needle in a branch of the saphenous vein.

It is evident that the transmission of so considerable a fraction of the intravascular pressure to the muscular tissue beneath the deep fascia of the leg provides in itself a partial compensation for the effects of gravity on the capillary pressure. Effective filtering pressure in these muscles is less, by 20 to $30 \mathrm{~cm} . \mathrm{H}_{2} \mathrm{O}$, than capillary pressure because the vessel walls do not support the full load of pressure. The contention of Henderson et al. (8) that muscles give support to the veins is therefore substantiated, but the support is chiefly due to the elasticity of fascia rather than to the contractile pressure of the muscle alone, as Henderson has suggested; for in loosely covered 

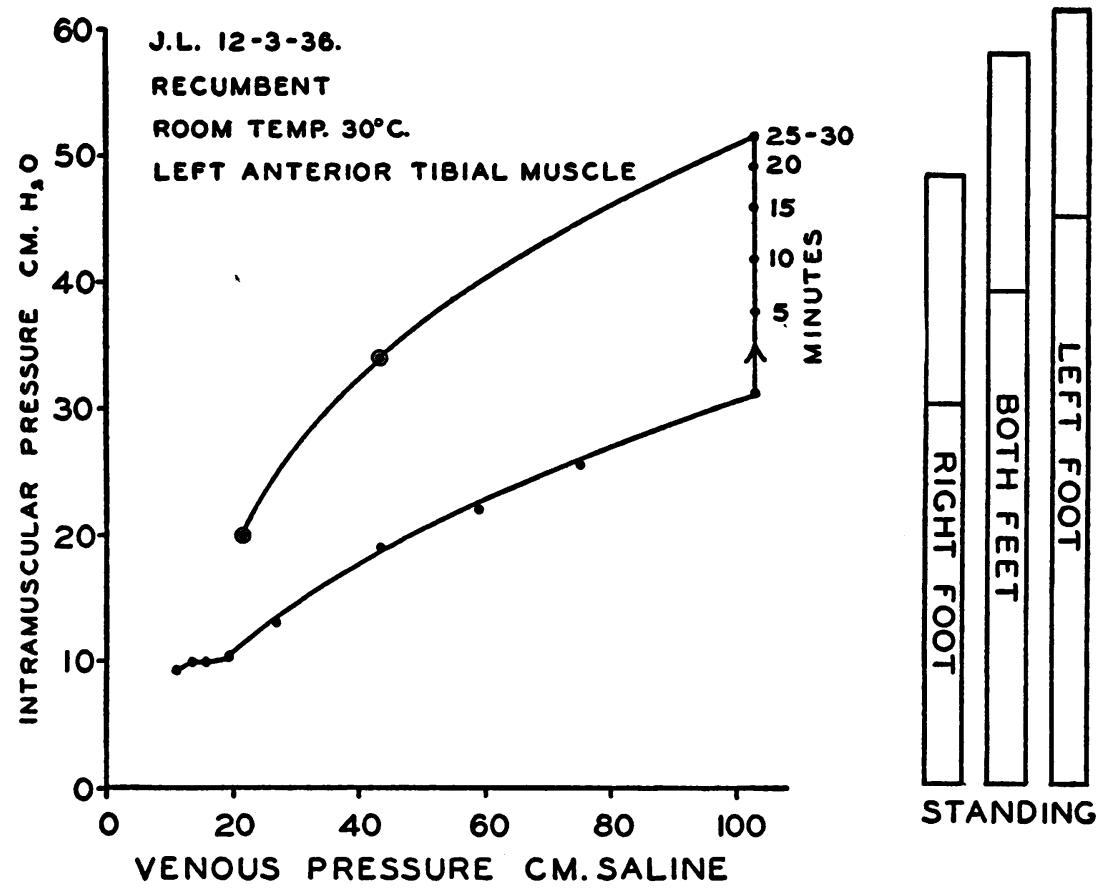

Fig. 5. Immediate Effects on Intramuscular Pressure of Increasing Venous Pressure by Congesting Cuff or Standing. Effects of Prolonged Congestion (Filtration) and of Graded Postural Tone of Muscles on Intramuscular Pressure

muscles like the gastrocnemius and biceps brachii neither venous congestion nor the most powerful voluntary contraction will raise intramuscular pressure to the high levels attained in the anterior tibial by venous congestion alone. Two experiments on anesthetized dogs showed that intramuscular pressure in the anterior tibial may be raised at once by venous congestion to values similar to those obtained in man. The protective mechanism afforded by fascia does not, therefore, appear to have undergone special evolutionary development in man to favor the erect posture. It is possible that fascia may be strengthened by exercise, as suggested by Waterfield (9), who found that subjects in good training showed less increase in volume of the leg during quiet standing than individuals in poor training.

(c) The relation of intramuscular pressure to capillary filtration. Prolonged venous congestion results in a progressive rise of intramuscular pressure. Final values up to $50 \mathrm{~cm} . \mathrm{H}_{2} \mathrm{O}$ and higher have been recorded from the anterior tibial muscle. Figure 5 shows the time course of pressure rise in this muscle for thirty minutes while venous pressure was maintained at $100 \mathrm{~cm} . \mathrm{H}_{2} \mathrm{O}$ by a congesting thigh cuff applied to the recumbent subject. The figure also shows the elevation of intramuscular pressure at the lower venous pressures of 20 and $40 \mathrm{~cm} . \mathrm{H}_{2} \mathrm{O}$ respectively following the prolonged congestion at $100 \mathrm{~cm}$.; and the columns to the right indicate the levels of intramuscular pressure in the same subject resulting from assumption of the erect posture, before and after the period of prolonged congestion referred to above. The effect of shifting the weight is also shown but these changes are of interest chiefly as they illustrate the effects of muscular contraction to be discussed in the section following.

Figure 6 depicts the time course of the rising pressure in the anterior tibial muscle during congestion produced by quiet standing.

Figure 7 presents the results of all experiments relating to the effect of prolonged venous congestion upon intramuscular pressure. It will be noted that initial and final pressures are much lower for the gastrocnemius than for the soleus or anterior tibial. 


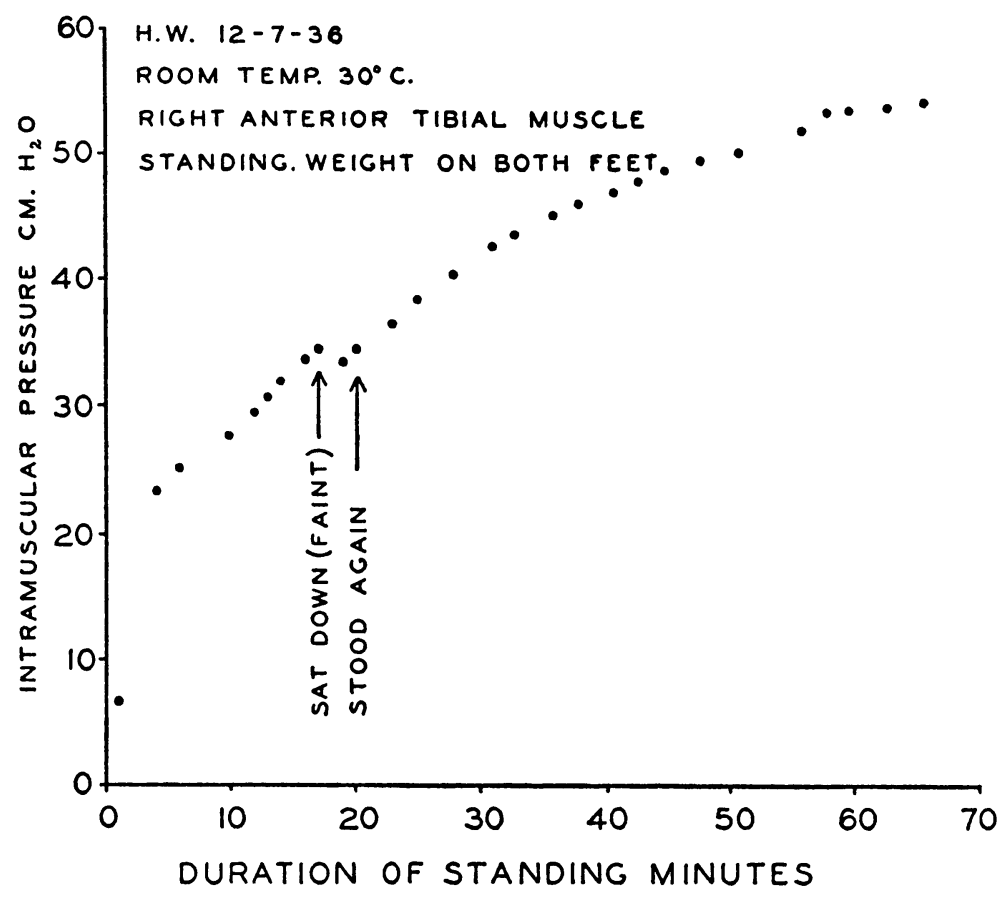

Fig. 6. Time Course of Rising Intramuscular Pressure during Prolonged Standing

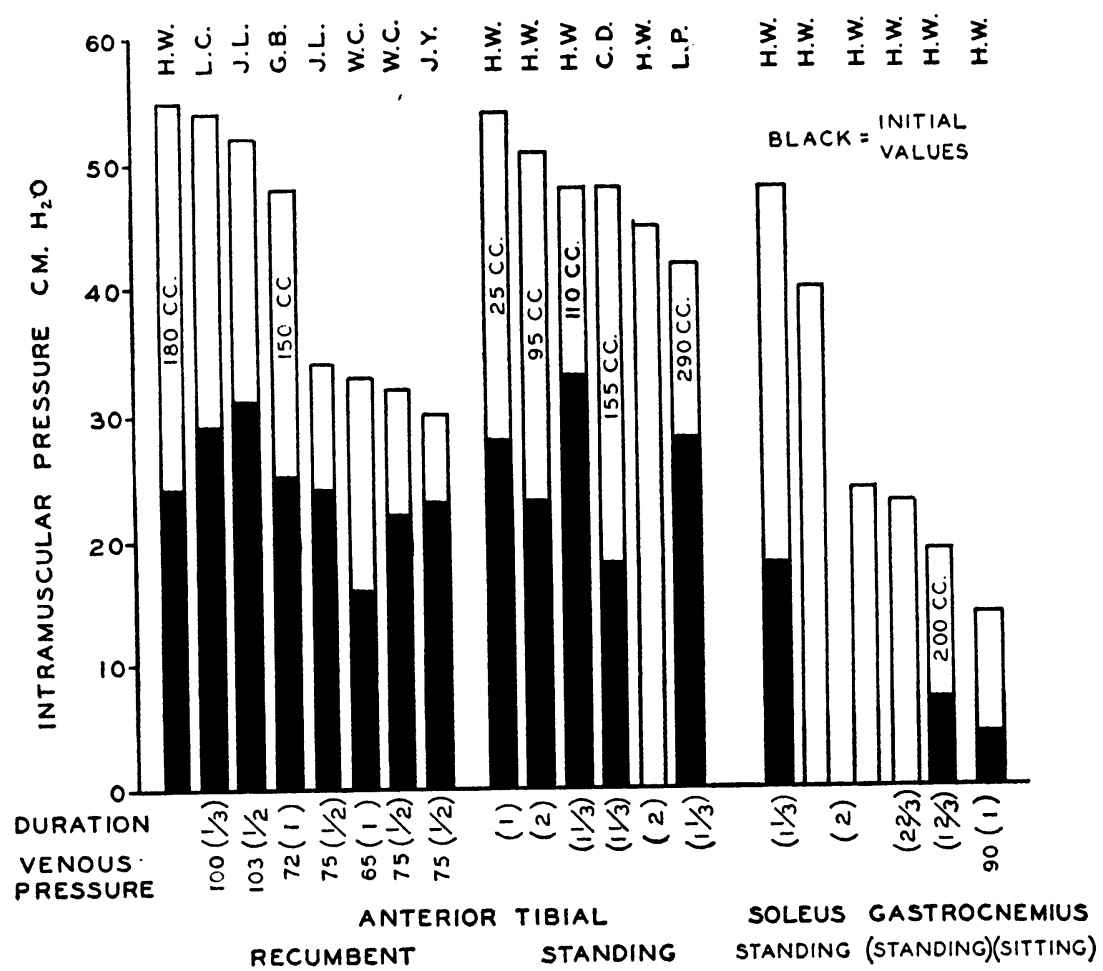

Fig. 7. Effects of Prolonged Congestion on Intramuscular Pressure in Various Muscles of Human Subjects 
It would appear that in the tightly covered muscles, as the soleus and anterior tibial, tissue pressure starts at a high level and increases quite rapidly to values which are of the magnitude required by Starling's hypothesis to effectively oppose further filtration. In the more loosely covered muscle, gastrocnemius, intramuscular pressure remains always at lower levels, which must be relatively ineffective in retarding filtration. The findings suggest that after filtration into high-pressure muscular tissue has ceased, fluid will continue to accumulate in the skin and gastrocnemius muscle and that the volume of the leg will increase continuously and indefinitely during quiet standing. Such a conclusion is contrary to the usual belief, which seems to be based chiefly on evidence presented by Waterfield (9), who found that leg volume, during standing, attained a maximum value within 40 minutes. Our own observations fail to confirm those of Waterfield. Leg volume continues to increase as long as the subject can stand, even up to 2.5 hours. However, we have observed that filtration, as determined by measuring changes in the volume of the leg in a water plethysmograph of the type employed by Waterfield, may be temporarily masked as the result of sharp vasoconstrictor reactions in the skin of the leg associated with the onset of acute abdominal discomfort, nausea, and tendency to syncope which invariably occur, at one time or another, during a prolonged period of standing. In trained subjects these reactions may be postponed to the second hour and they are less intense, but in untrained subjects they usually appear within the first hour and are apt to become so severe as to terminate the experiment. The probable effect of these vasomotor reactions to force a small amount of blood from the skin and thus to mask the accumulation of fluid within the tissue during the same period requires further study, but it is our belief that such effects may have been responsible for the results obtained by Waterfield. Our findings are supported to some extent by the experiments of Smirk (7) who found that the hand continues to swell for at least five hours after venous congestion has been developed in the arm. Furthermore, Drury and Jones (10) were able to develop edema in the leg of a normal subject by congesting the limb for 220 minutes. Leg volume was still increasing at the end of the pe- riod, at one-third the initial rate. These authors have shown that a high skin temperature increases the rate of filtration, and in this experiment the leg was exposed to water at $36^{\circ} \mathrm{C}$. Our own experiments have been performed at temperatures ranging from $22^{\circ}$ to $36^{\circ} \mathrm{C}$., and in all cases filtration continued throughout the duration of the observation. Atzler and Herbst (11) report that leg volume continues to increase for two hours during quiet standing. In one experiment which extended to three hours they report a decrease in leg volume of $4 \mathrm{cc}$., which occurred during the last hour; and on the basis of this single experience the authors conclude that leg volume will always attain a maximum value after two hours. Such a conclusion does not seem justified by their data. The decrease in volume which they actually observed can best be explained as due to a vasomotor reaction.

The rates of filtration during congestion of the leg and ratios of final to initial rates, calculated from our data and from figures published by Drury and Jones and by Atzler and Herbst, are recorded in Table $I$.

(d) Direct and indirect effects of muscular contraction on intramuscular pressure. As shown in Figure 8, maximal voluntary tensing of muscles will, in some cases, raise intramuscular pressure to considerable heights. However, in relation to the contractile force of these muscles the intramuscular pressure is perhaps lower than one might expect to find it. The leg muscles of our human subject (H. W.) were fairly well developed and it was surprising indeed that the pressure in the rectus femoris, for example, could not be raised above $20 \mathrm{~cm} . \mathrm{H}_{2} \mathrm{O}$ with the greatest possible voluntary contraction. Figures for the gastrocnemius were not obtainable because of the peculiar sickening pain felt in this muscle when it contracts upon the needle, a quality of sensation quite different in degree, and perhaps in quality, from that perceived in studies on other muscles. A pressure of $31 \mathrm{~cm} . \mathrm{H}_{2} \mathrm{O}$ has been reported by Henderson, et al. (8) for the gastrocnemius of a human subject during maximal voluntary contraction.

The values of the pressure during maximal contraction are of interest, first, in relation to the work of Anrep, Blalock, and Samaan (12) who found that blood flow through muscles of experi- 
TABLE I

Filtration rates and ratios during prolonged congestion of the leg

\begin{tabular}{|c|c|c|c|c|c|c|c|}
\hline \multirow{2}{*}{ Subject } & \multirow{2}{*}{ Conditions } & \multirow{2}{*}{\multicolumn{2}{|c|}{$\begin{array}{c}\begin{array}{c}\text { Temperature } \\
\text { of }\end{array} \\
\text { Water in } \\
\text { Boot / Air }\end{array}$}} & \multirow{2}{*}{$\underset{\text { tion }}{\text { Dura- }}$} & \multicolumn{2}{|c|}{ Filtration rates } & \multirow{2}{*}{$\begin{array}{c}\begin{array}{c}\text { Filtration } \\
\text { ratios }\end{array} \\
\text { Final rate } \\
\text { Initial rate }\end{array}$} \\
\hline & & & & & Initial & Final & \\
\hline \multirow{3}{*}{$\begin{array}{l}\text { H. W........ } \\
\text { H. W....... } \\
\text { H. W........ } \\
\text { H. W....... }\end{array}$} & \multirow{3}{*}{$\begin{array}{l}\text { Standing in boot; weight on opposite leg. } \\
\text { Standing on floor; weight on opposite leg; volume, } \\
\text { sitting. in boot; weight on opposite leg. } \\
\text { Standing in btarted } 1 \\
\text { Standing in bot; weight on opposite leg. Started } \\
\text { hour after preceding experiment. }\end{array}$} & $\begin{array}{c}{ }^{\circ} C . \\
20-23\end{array}$ & $\begin{array}{l}\circ C \\
21\end{array}$ & $\begin{array}{c}\text { minutes } \\
120\end{array}$ & $\begin{array}{c}c c . \text { per } 100 \\
\text { cc. per } \\
\text { minute } \\
0.055\end{array}$ & $\begin{array}{l}c c . \text { per } 100 \\
\text { cc. per } \\
\text { minute } \\
0.012\end{array}$ & 0.21 \\
\hline & & $\begin{array}{l}24-25.5 \\
29\end{array}$ & $\begin{array}{l}25 \\
30\end{array}$ & $\begin{array}{r}150 \\
80\end{array}$ & $\begin{array}{l}0.111 \\
0.087\end{array}$ & $\begin{array}{l}0.0135 \\
0.0155\end{array}$ & $\begin{array}{l}0.12 \\
0.18\end{array}$ \\
\hline & & 36 & 32 & 150 & 0.064 & 0.009 & 0.14 \\
\hline \multicolumn{8}{|l|}{ Author } \\
\hline $\begin{array}{l}\text { Drury and } \\
\text { Jones }(10)\end{array}$ & $\begin{array}{l}\text { Sitting; leg in boot; congesting cuff pressure, } 60 \mathrm{~mm} \text {. } \\
\text { Hg. }\end{array}$ & 36 & & 220 & 0.066 & 0.022 & 0.33 \\
\hline Herbst (11) & Standing; volume, sitting. & & & $\begin{array}{l}120 \\
120 \\
120 \\
120 \\
120\end{array}$ & $\begin{array}{l}0.115 \\
0.052 \\
0.054 \\
0.055 \\
0.072\end{array}$ & $\begin{array}{l}0.015 \\
0.015 \\
0.007 \\
0.018 \\
0.014\end{array}$ & $\begin{array}{l}0.13 \\
0.29 \\
0.13 \\
0.24 \\
0.19\end{array}$ \\
\hline
\end{tabular}

mental animals was much retarded and might even cease when powerful contractions were elicited either reflexly or by direct stimulation of the muscle or its motor nerve. No doubt blood flow may be retarded during ordinary contractions in man, but it is probable that only a convulsive contraction or cramp can completely occlude the arteries of the limb. Levels of intramuscular pressure which might conceivably be high enough to stop the flow of blood were observed in man only in the lower part of the soleus muscle, beneath the thick investing layer of origin of the Achilles tendon; and in the dog, in the anterior tibial muscle during a maximal isometric contraction resulting from stimulation of the sciatic nerve. We concur with the conclusion of Henderson, which was based on the single observation mentioned above, that voluntary contractions of most human muscles are not ordinarily powerful enough to stop the flow of blood in intramuscular arteries, for the pressures observed in muscles are, in the main, definitely below the diastolic level of arterial pressure.

Maximal values of intramuscular pressure are of interest from another viewpoint, for these pressures, in most muscles, will not suffice to collapse even the veins, when venous pressure is elevated during quiet standing to the usual levels of $90 \mathrm{~cm} . \mathrm{H}_{2} \mathrm{O}$ or higher. The veins can be only partially collapsed by a single contraction, and more than one contraction will be required to completely empty a section of vein below a competent valve. It follows also that after venous pressure has risen above the level of maximal intramuscular pressure, contraction of the muscles would be completely ineffective for pumping blood from the veins if these vessels did not possess their normal property of distensibility, which enables them to expand under pressure like tubes of rubber. If the walls of the veins should become indistensible, though not necessarily rigid, the venous pump would fail to act, in the erect posture, regardless of the condition of the venous valves. Under these conditions a subject whose valves were normal might develop some of the circulatory changes usually associated with valvular incompetence.

Our studies indicate, further, that leg volume may or may not increase less rapidly while the muscles of the leg are held tense, as by standing with the weight entirely on the leg in question; for, although the increase in tissue pressure resulting from contraction would be expected to retard filtration into the muscles, as claimed by 


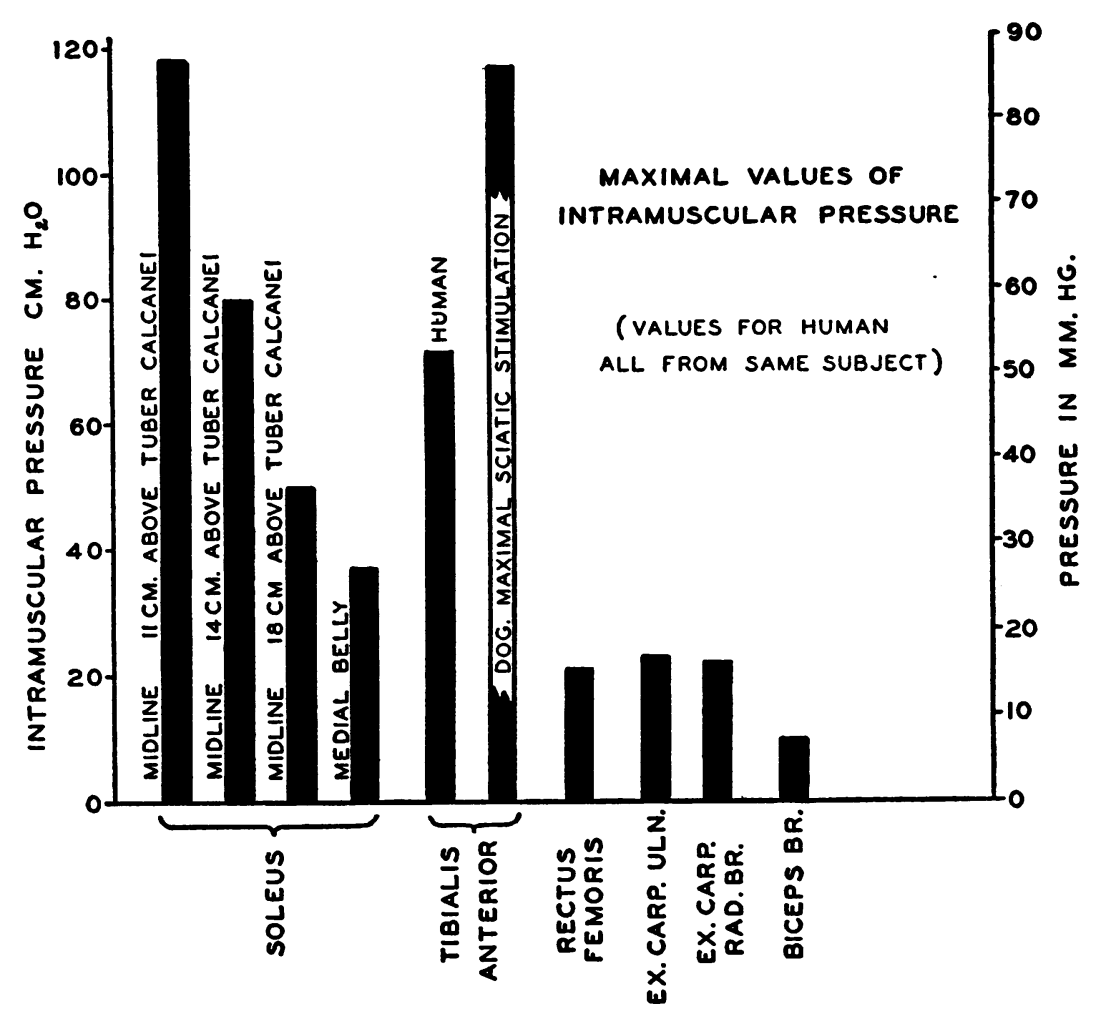

Fig. 8. Maximal Values of Intramuscular Pressure during Voluntary Contractions in Man and during Maximal Sciatic Stimulation in THE DOG

Waterfield (9), the prolonged contraction undoubtedly causes more capillaries to open up. Furthermore, it is difficult to maintain a steady tension of the muscles. Alternate contraction and relaxation, with the resulting lowering of venous and hence capillary pressure is apt to occur. Our experiments indicate a lower rate of filtration at first, followed by a gradually increasing rate; but the results were not sufficiently regular, for reasons stated above, to warrant definite conclusions.

The increase of intramuscular pressure, due to the effect of muscular contraction, is intensified after prolonged congestion as shown in Figure 5. Contraction was graded fairly accurately in this experiment by shifting the weight of the body first to both legs and then to the experimental leg alone. The pressure increased in two steps as indicated. The effect is doubtless due to the accumulation of fluid within the muscle as the result of filration.
The elevation of intramuscular pressure resulting from a muscular contraction may be partly attributed to components of force exerted by the contractile elements-the tense muscle may tend to "hug" the bone; but the fascial covering would seem to be of great importance for directing these forces inward at points where the muscle thickens during contraction. An exact analysis of the forces involved must await further investigation.

\section{DISCUSSION}

Special aspects of the results have been discussed under appropriate headings above. It remains to inquire how tissue pressure can affect the rate of accumulation of edema fluid and the rate of increase of leg volume during quiet standing.

It is clear that when intramuscular pressure in the leg rises to $50 \mathrm{~cm} . \mathrm{H}_{2} \mathrm{O}$ or higher during congestion at an average venous pressure of $90 \mathrm{~cm}$. 
$\mathrm{H}_{2} \mathrm{O}$ or thereabouts filtration into the muscles in question will probably cease, for the estimated effective filtering pressure- $40 \mathrm{~cm} \cdot \mathrm{H}_{2} \mathrm{O}$-is no longer higher than the probable value for effective osmotic pressure. The colloid osmotic pressure of plasma proteins may be expected to rise to about $50 \mathrm{~cm} . \mathrm{H}_{2} \mathrm{O}(2)$ as the result of concentration of the blood in filtering areas, and, allowing for some leakage of protein through the capillary wall (13), a value of $40 \mathrm{~cm} . \mathrm{H}_{2} \mathrm{O}$ for the effective osmotic pressure seems to be a reasonable figure.

Since tissue pressure in the skin, subcutaneous tissues, and gastrocnemius muscle does not rise above 15 to $20 \mathrm{~cm} . \mathrm{H}_{2} \mathrm{O}$, effective filtering pressure $(90-20=70)$ must remain considerably higher than osmotic pressure, and it can therefore be concluded that filtration must continue in these areas as long as the subject continues to stand. If leg volume should attain a constant value within the first hour, as claimed by Waterfield (9) one would be forced to conclude that fluid can be removed from the leg as fast as it filters from the capillaries of these low-pressure tissues. Such removal might be imagined to take place by lymphatic drainage of the area, but it is very unlikely that lymph escapes from the leg at all during standing, in the absence of movements of the muscles or joints. Since we find, in fact, that the leg does continue to increase in volume for at least 2.5 hours it would be necessary to invoke an additional balancing factor, such as lymphatic drainage, only if the final rate of swelling of the leg could be shown to be so very slow, relative to the initial rate, that the retardation could not be attributed solely to the known increments of osmotic and tissue pressures. As a matter of fact the following calculations indicate that cessation of filtration in the large mass of muscles of the leg, as tissue pressure rises in these high-pressure regions, is chiefly accountable for the low residual rate of swelling of the leg.

The leg of a cadaver, a well developed male subject, was dissected and the parts weighed. The skin weighed $0.33 \mathrm{kgm}$. (18 per cent of the total weight of skin and muscles), the gastrocnemius weighed $0.36 \mathrm{kgm}$. (19 per cent of the total) and all other leg muscles weighed together $1.185 \mathrm{kgm}$. ( 63 per cent of the total). The subcutaneous tissue was neglected, for the number of open capillaries available for filtration is probably minimal in this tissue. The tissues of the foot were also neglected, on the assumption that the relative weights are similar to those of the leg. Assuming that, aside from differences in tissue pressure, filtration occurs at the same rate, per unit weight of tissue, in skin and all muscles; that average capillary pressure throughout the leg remains at $90 \mathrm{~cm} . \mathrm{H}_{2} \mathrm{O}$ during standing ; that effective osmotic pressure rises from an initial value of $30 \mathrm{~cm}$. to a final value of $40 \mathrm{~cm} . \mathrm{H}_{2} \mathrm{O}$; and that initial and final values of tissue pressure are: in skin, 5 and $15 \mathrm{~cm} . \mathrm{H}_{2} \mathrm{O}$; in the gastrocnemius, 5 and $20 \mathrm{~cm} . \mathrm{H}_{2} \mathrm{O}$; and in all other muscles 25 and $50 \mathrm{~cm} . \mathrm{H}_{2} \mathrm{O}$ respectively; one can calculate, using the relative weights of these tissues as determined, that the ratio of final to initial filtration rates will be 0.27 . If tissue pressure did not rise above its initial value in the high-pressure muscles the ratio would be 0.65 , showing that the rise in intramuscular pressure which is actually observed has a marked effect to retard filtration. Since variations in skin temperature are known to affect profoundly the rate of increase of leg volume, we may profitably inquire to what degree a relative change in rate of filtration in skin alone will affect the calculated ratios of final to initial filtration in the leg. If filtration occurs at twice the rate in skin as in muscle, the ratio rises to 0.33 ; if filtration in skin starts at one-half the rate for an equivalent weight of muscle, the ratio drops to 0.23 ; if the cutaneous rate is one-fourth the standard rate for muscle, the ratio is reduced to 0.21 ; and if we can assume that filtration starts in the skin at the standard rate but stops entirely during a phase of vasoconstriction affecting this tissue alone, the ratio falls to 0.14 . It is of interest to note that the range of calculated ratios ( 0.14 to 0.33 ) very nearly covers the range of observed ratios $(0.12$ to 0.33 ) presented in Table $I$.

It is not our intention to place undue emphasis on the particular values of the calculated ratios. The calculations are merely helpful to indicate the approximate relationships of the known variables which affect the rate of swelling of the leg during quiet standing and to show that, in all probability, the observed changes in osmotic pressure and tissue pressure are sufficient to account for the changes in filtration rates, if a reasonable allowance is also made for changes in the filtering area incident to vasomotor reactions. 


\section{SUM MARY}

1. Subcutaneous and intracutaneous pressures are never greatly elevated in normal subjects following prolonged venous congestion of the leg and in most cases the rise is insignificant.

2. The pressure in those leg muscles which are tightly covered with fascia rises to $50 \mathrm{~cm} . \mathrm{H}_{2} \mathrm{O}$ or higher during prolonged venous congestion. Pressures of this magnitude probably suffice to stop filtration into these muscles during quiet standing. Pressure in the gastrocnemius, which is loosely covered, does not rise above $20 \mathrm{~cm} . \mathrm{H}_{2} \mathrm{O}$ during congestion.

3. Intramuscular pressure is affected independently by several factors, of which the most important are: the tightness of the fascia, the amount of intravascular and extravascular fluid present, and the components of contractile force of the muscle. Intramuscular pressure cannot be used as an index of muscle tonus unless all of these factors are controlled.

4. Maximal voluntary contractions of various muscles elevate intramuscular pressure to values ranging from 10 to $118 \mathrm{~cm} . \mathrm{H}_{2} \mathrm{O}$. As these values, in most muscles, are lower than the level of diastolic arterial pressure, blood flow through these muscles cannot be stopped during ordinary contractions. Relations of intramuscular pressure to the venous pump mechanism are discussed.

5. Leg volume continues to increase indefinitely (at least for 2.5 hours) during quiet standing. In each case the ratio of the final rate of filtration to the initial rate is of the magnitude to be expected on the assumption that filtration ceases in high-pressure muscles but continues indefinitely in the skin and gastrocnemius, the low pressure filtering areas. It is not necessary to assume that fluid leaves the leg through lymphatics during quiet standing.

\section{BIBLIOGRAPHY}

1. Landis, E. M., and Gibbon, J. H., Jr., The effect of temperature and of tissue pressure on the movement of fluid through the human capillary wall. J. Clin. Invest., 1933, 12, 105.

2. Youmans, J. B., Wells, H. S., Donley, D., and Miller, D. G., The effect of posture (standing) on the serum protein concentration and colloid osmotic pressure of blood from the foot in relation to the formation of edema. J. Clin. Invest., 1934, 13, 447.

3. Meyer, F., and Holland, G., Die Messung des Druckes in Geweben. Arch. f. exper. Path. u. Pharmakol., 1932, 168, 580.

4. Holland, G., and Meyer, F., Der Gewebsdruck beim Ödem. Arch. f. exper. Path. u. Pharmakol., 1932, 168, 603.

5. Burch, G. E., and Sodeman, W. A., The estimation of the subcutaneous tissue pressure by a direct method. J. Clin. Invest., 1937, 16, 845.

6. Youmans, J. B., Akeroyd, J. H., and Frank, Helen, Changes in the blood and circulation with changes in posture. The effect of exercise and vasodilatation. J. Clin. Invest., 1935, 14, 739.

7. Smirk, F. H., Observations on the causes of oedema in congestive heart failure. Clin. Sc., 1935-36, 2, 317.

8. Henderson, Y., Oughterson, A. W., Greenberg, L. A., and Searle, C. P., Muscle tonus, intramuscular pressure and the venopressor mechanism. Am. J. Physiol., 1935-36, 114, 261.

9. Waterfield, R. L., The effect of posture on the volume of the leg. J. Physiol., 1931, 72, 121.

10. Drury, A. N., and Jones, N. W., Observations upon the rate at which oedema forms when the veins of the human limb are congested. Heart, 1927, 14, 55.

11. Atzler, E., and Herbst, R., Die Schwankungen des Fussvolumens und deren Beeinflussung. Ztschr. f. d. ges. exper. Med., 1923, 38, 137.

12. Anrep, G. V., Blalock, A., and Samaan, A., The effect of muscular contraction upon the blood flow in the skeletal muscle. Proc. Roy. Soc. London, s.B., 1933-34, 114, 223.

13. Landis, E. M., Jonas, L., Angevine, M., and Erb, W., The passage of fluid and protein through the human capillary wall during venous congestion. J. Clin. Invest., 1932, 11, 717. 